\title{
Effects of artichoke leaf extract on hepatic ischemia- reperfusion injury
}

\author{
Salih Celepli ${ }^{*}$ (D), Bayram Çolak² (D), Pınar Celepli ${ }^{3}$, Irem Bigat ${ }^{4}$ (D), Hatice Gül Batur ${ }^{5}$ (D), \\ Furkan Soysal $^{6}$ (D), Serdar Karakurt ${ }^{5}$ (D), Sema Hücümenoğlu ${ }^{\text {(D) }}$, Kemal Kısmet ${ }^{7}$ (D), Mustafa Şahin ${ }^{2}$
}

\begin{abstract}
SUMMARY
OBJECTIVE: The aim of this study was to evaluate the hepatoprotective effect and mechanism of action of artichoke leaf extract in hepatic ischemia/ reperfusion injury.

METHODS: Rats were divided into three groups such as sham, control, and artichoke leaf extract groups. Antioxidant enzyme activities and biochemical parameters were examined from the tissue and serum obtained from the subjects. Histopathological findings were scored semiquantitatively. RESULTS: Statistically, the antioxidant activity was highest in the artichoke leaf extract group, the difference in biochemical parameters and C-reactive protein was significant compared with the control group, and the histopathological positive effects were found to be significantly higher.

CONCLUSIONS: As a result, artichoke leaf extract had a hepatoprotective effect and that this effect was related to the antioxidant and antiinflammatory effects of artichoke.

KEYWORDS: Liver. Ischemia-reperfusion. Artichoke. Hepatoprotective. Antioxidant.
\end{abstract}

\section{INTRODUCTION}

Liver ischemia/reperfusion (I/R) injury develops due to hypoperfusion that occurs during trauma and surgery of the liver and due to macrophage activation, that occurs after reperfusion. Excessive amounts of reactive oxygen species (ROS) released as a result of the stimulation of macrophages bind to cellular macromolecules (including DNA, proteins, and lipids), causing tissue damage and cell death ${ }^{1,2}$.

Despite many experimental studies in the literature, it can be seen that an effective pharmacological strategy against $\mathrm{I} / \mathrm{R}$ injury has not yet been developed. To create an effective treatment method in this area, there is ongoing research into natural agents rich in flavonoids, anthocyanins, and other phenolic compounds that effectively treat $I / R^{3}$. Many studies have shown that artichoke leaf extract (ALE), rich in phenolic compounds and caffeic acid derivatives, provides a hepatoprotective effect by significantly preventing oxidative damage in hepatocyte membranes. It has been reported in many studies in the literature that ALE exhibits both nephroprotective and hepatoprotective properties in paracetamol and cadmium-induced toxicity ${ }^{4-7}$.
Although various studies show the hepatoprotective effect of ALE, there is no study evaluating its efficacy in hepatic I/R injury. Therefore, this study aimed to assess whether or not ALE has a hepatoprotective effect in hepatic I/R injury and the mechanisms of this effect.

\section{METHODS}

This study was carried out by following the principles of the National Laboratory Animal Use and Care Directive, with the approval of the Animal Ethics Committee of Selçuk University Experimental Medicine Research Center. A total of 30 adult male Wistar albino rats, each weighing $300 \pm 25 \mathrm{~g}$, were included in this study. No rats were given parenteral or enteral antibiotics throughout the experiment. The rats were randomly separated into three groups of 10 rats in each. All the rats were intramuscularly anesthetized with $50-\mathrm{mg} / \mathrm{kg}$ ketamine hydrochloride (Ketalar ${ }^{\oplus}$; Parke-Davis, Istanbul, Turkey) and 10-mg/kg xylazine (Rompun ${ }^{\oplus}$; Bayer, Istanbul, Turkey). Ischemia was created by clamping the hepatic artery and portal vein for $60 \mathrm{~min}$,

\footnotetext{
${ }^{1}$ Gülhane Training and Research Hospital, Department of General Surgery - Ankara, Turkey.

${ }^{2}$ Selçuk University, Faculty of Medicine, Department of General Surgery - Konya, Turkey.

${ }^{3}$ Ankara Training and Research Hospital, Department of Pathology - Ankara, Turkey.

${ }^{4}$ TOBB University of Economics \& Technology, Department of Biomedical Engineering - Ankara, Turkey.

${ }^{5}$ Selçuk University, Science Faculty, Biochemistry Department - Konya, Turkey.

${ }^{6}$ Ankara Yıldırım Beyazıt University, Faculty of Engineering and Natural Sciences, Department of Chemical Engineering - Konya, Turkey.

${ }^{7}$ Selçuk University, Faculty of Nursing, Department of Surgical Nursing - Konya, Turkey.

${ }^{*}$ Corresponding author: dr.salih.celepli@gmail.com

Conflicts of interest: the authors declare there is no conflicts of interest. Funding: none.

Received on September 22, 2021. Accepted on September 24, 2021.
} 
and then liver tissue and blood samples were taken at the 90th minute of reperfusion.

Group I (sham group): Laparotomy and hepatic pedicle mobilization were performed on the rats, and liver tissue and blood samples were taken at the end of $90 \mathrm{~min}$.

Group II (control group): I/R model was performed without any medication.

Group III (artichoke extract group): The rats in this group were given ALE at a $300 \mathrm{mg} / \mathrm{kg}$ dose via orogastric tube $2 \mathrm{~h}$ before the operation.

The dose of artichoke extract was planned to be $300 \mathrm{mg} / \mathrm{kg}$, with reference to the information obtained from scanning many articles in the literature. The extract was generally administered as oral gavage in these studies ${ }^{8,9}$.

\section{Artichoke leaf extract preparation}

The ALE used in this study was prepared at the Faculty of Engineering and Natural Sciences, Department of Chemical Engineering, Ankara Yıldırım Beyazıt University. Artichoke leaves were cut into small slices and dried in an oven at $103^{\circ} \mathrm{C}$ until a constant weight is obtained. The dried artichoke leaves were ground into powder and placed in a test tube, then $10 \%$ $(\mathrm{v} / \mathrm{v})$ aqueous acetonitrile solution was added to stabilize the extract. Aqueous methanol solution $(70 \%)$ was added at $70^{\circ} \mathrm{C}$, then the mixture was mixed in an ultrasonic bath and kept at $70^{\circ} \mathrm{C}$ in a water bath for $10 \mathrm{~min}$. The test tube was brought to room temperature, centrifuged at $3500 \mathrm{rpm}$ for $10 \mathrm{~min}$, and the supernatant was then transferred to another container.

\section{Determination of total \\ phenolic/flavonoid antioxidant amounts}

The obtained extract was diluted 100-fold with deionized water. Notably, $1 \mathrm{~mL}$ of diluted extract, $5 \mathrm{~mL}$ of Folin-Ciocalteu reagent, and $4 \mathrm{~mL}$ of sodium carbonate solution were put into a plastic tube and mixing in intermediate steps was done accordingly. Resulting solution was analyzed with UV-vis spectrophotometer, and absorbance values at $765 \mathrm{~nm}$ were recorded. Calibration curve was generated using the absorbance values at $765 \mathrm{~nm}$, and calibration equation was found. Absorbance values at $765 \mathrm{~nm}$ were used to calculate the total polyphenol content of the sample by the calibration equation. For the total phenolic amount of ALE as gallic acid equivalent (GAE), the total flavonoid amount was calculated using quercetin equivalent $(\mathrm{QE})$ as the standard.

\section{Biochemical evaluations}

At the end of the experiment, liver tissue and blood samples were obtained from the rats. Tissues were washed with cold distilled water and physiological serum, and blood was removed and frozen in liquid nitrogen in a sterile manner. The samples were taken to the Research Laboratory of the Biochemistry Department of the Faculty of Science. Serum was obtained by centrifuging the blood at $10,000 \mathrm{rpm}$ for five min at $4^{\circ} \mathrm{C}$. Frozen tissues were minced on ice, and homogenization was performed in a Potter-Elvehjem glass Teflon homogenizer placed on ice. The resulting homogenate was centrifuged to remove cellular debris, and the supernatant was separated from the pellet by filtering through a double layer of sterile gauze and centrifuged again. Finally, the supernatant from the obtained fraction was poured off, and 0.5 times the initial tissue weight of cold suspension buffer ( 2 mM EDTA, pH 7.5; 10\% glycerin) was added to the pellet, homogenized by hand, and stored at $-80^{\circ} \mathrm{C}$ until the assay.

The activity measurement of the catalase (CAT), superoxide dismutase (SOD), and glutathione peroxidase (GPx) enzymes was determined using the spectrophotometric method of Aebi ${ }^{8}$, Marklund and Marklund ${ }^{9}$, and Paglia and Valentine ${ }^{10}$, respectively. Aspartate aminotransferase (AST) and alanine aminotransferase (ALT) activities were determined spectrophotometrically using Reitman and Frankel's method ${ }^{11}$.Lactate dehydrogenase (LDH) measurement was made with the spectrophotometric method optimized by Wroblewski and $\mathrm{LaDue}^{12}$. In addition, total bilirubin (TBIL), direct bilirubin (DBIL), alkaline phosphatase (ALP), C-reactive protein (CRP), creatine kinase (CK), total protein (TPROT), and albumin (ALB) levels were measured using appropriate methods.

\section{Measurement of gene and protein expressions}

The determination of ALB, fibrinogen, and prothrombin amounts of microsomal fractions obtained from tissues was made with Lowry et al.'s method using BSA (bovine serum albumin) as a standard ${ }^{13}$. The obtained proteins were evaluated with the western blot method following vertical electrophoresis and sodium dodecyl sulfate polyacrylamide gel electrophoresis (SDS-PAGE).

To determine the effects of the studied plant components on the gene expression levels of the enzymes, RNA isolation from the tissues obtained was performed using the RNA TRIZOL method $^{14}$. In this study, ALB, fibrinogen, and prothrombin RNA were isolated. The complementary DNA (cDNA) synthesis from the obtained RNAs was performed using the iScript ${ }^{\mathrm{Tm}}$ cDNA Synthesis Kit. Quantitative real-time polymerase chain reaction (qRT-PCR) studies were performed using the CFXConnect Real-Time PCR system (Bio-Rad, USA). Changes in gene expressions were detected by calculating the ratio of 
specific gene messenger RNA (mRNA) expressions to mRNA expression of housekeeping genes $\left(2^{-\Delta \Delta \mathrm{C}_{\mathrm{t}}}\right)$. The primers used were designed using Primer 3 software and their specificity was checked by the National Center for Biotechnology Information.

\section{Histopathological assessments}

After the liver tissues were fixed in 10\% formalin solution for $24 \mathrm{~h}$, standard dehydration procedures were applied and then the samples were blocked in paraffin. A $4-\mu \mathrm{m}$ thickness section was cut from the blocks, prepared, and stained with hematoxylin and eosin. These prepared tissue samples were examined under an OLYMPUS BX51TF model light microscope. The histopathological findings of the liver were scored semiquantitatively from $0-4$ by evaluating sinusoidal congestion, hepatocyte necrosis, and liver cell vacuolization with the modified Suzuki score ${ }^{15}$.

\section{Statistical analysis}

Biochemical data were analyzed using the Statistical Package for Social Sciences (SPSS) version 23.0 for Windows software (SPSS Inc., Chicago, IL, USA). All variables were found to be normally distributed with respect to the mean. Therefore, the data were presented as mean \pm standard deviation $(\mathrm{SD})$ values. A $p<0.05$ was considered statistically significant.

Statistical analysis of the pathological scores was performed using R 3.6.0 software (https://www.r-poject.org). The data were reported as number (n) and percentage (\%). A chi-square test was conducted to examine the association between histopathological scores and study groups. Since the proportion of cells with the expected value $<5$ was more than $20 \%$, p-values were calculated with Monte Carlo simulation. After the $\chi^{2}$ test, the two-proportion $\mathrm{Z}$ test with Bonferroni adjustment was used for multiple comparisons. A $\mathrm{p}<0.05$ was considered statistically significant.

\section{RESULTS}

\section{Determination of total phenolic/flavonoid antioxidant amounts}

For the total phenolic amount of ALE as GAE, the total flavonoid amount was calculated using $\mathrm{QE}$ as the standard. The total phenolic and flavonoid amount was found to be $38.03 \pm 0.95 \mu \mathrm{g} \mathrm{GAE} / \mathrm{mg}$ and $18.11 \pm 0.26 \mu \mathrm{g} \mathrm{QE} / \mathrm{mg}$, respectively.

\section{Biochemical analysis results}

The results of the biochemical analyses are given in Tables 1 and 2. According to these results, the CRP values in the control group were found to be statistically significantly higher than those in the sham and artichoke groups $(\mathrm{p}<0.05)$. No significant difference was observed between the sham and artichoke groups in CRP values ( $p>0.05$ ). Similarly, ALT, AST, LDH, ALP, and CK values were significantly higher in the control group than those in the sham and artichoke groups $(\mathrm{p}<0.05)$. The values of all these parameters were higher in the artichoke group than those in the sham group. A statistically significant difference was observed between the sham and artichoke groups in all the other parameters, except for $\mathrm{CK}(\mathrm{p}<0.05)$. No significant difference was determined between the groups regarding the TPROT, ALB, TBIL, and DBIL values $(\mathrm{p}>0.05)$.

\section{Antioxidant enzyme activities}

In evaluating the results of SOD, CAT, and GPx, which are the parameters used to assess antioxidant enzyme activities, antioxidant activity in the artichoke group was statistically significantly higher than that in the other two groups $(\mathrm{p}<0.05)$. In contrast, no statistically significant difference was found between the SOD and CAT values of the sham and control groups ( $\mathrm{p}>0.05)$.

When ALB, fibrinogen, and prothrombin protein expressions and ALB, fibrinogen, and prothrombin gene expressions

Table 1. Average values of biochemical parameters.

\begin{tabular}{l|c|c|c|c|c} 
Groups & CRP & ALT & AST & LDH & ALP \\
\hline $\begin{array}{l}\text { Group 1 } \\
\text { (Sham) }\end{array}$ & $0.16 \pm 0.07^{\mathrm{a}}$ & $181.22 \pm 14.48^{\mathrm{a}, \mathrm{b}}$ & $181.77 \pm 48.82^{\mathrm{a}, \mathrm{b}}$ & $1667.77 \pm 144.98^{\mathrm{a}, \mathrm{b}}$ & $64.55 \pm 10.36^{\mathrm{a}, \mathrm{b}}$ \\
\hline $\begin{array}{l}\text { Group 2 } \\
\text { (Control) }\end{array}$ & $0.33 \pm 0.13^{\mathrm{c}}$ & $511.52 \pm 28.64^{\mathrm{c}}$ & $800.80 \pm 68.89^{c}$ & $4239.12 \pm 186.88^{c}$ & $280.12 \pm 71.45^{c}$ \\
\hline $\begin{array}{l}\text { Group 3 } \\
\text { (Artichoke) }\end{array}$ & $0.18 \pm 0.05$ & $224.10 \pm 21.28$ & $567.03 \pm 54.68$ & $2379.60 \pm 114.34$ & \pm 28.66 \\
\hline
\end{tabular}

CRP: C-reactive protein; ALT: alanine aminotransferase; AST: aspartate aminotransferase; ALP: alkaline phosphatase. ${ }^{2}$ Statistically significant difference between Group 1 versus Group 2. 'Statistically significant difference between Group 1 versus Group 3. ‘Statistically significant difference between Group 2 versus Group 3. 
were evaluated, it was observed that there was no statistically significant difference between the groups $(\mathrm{p}>0.05)$.

\section{Histopathological results}

The comparisons of the histopathological scores of the study groups are shown in Table 3. A statistically significant association was determined between the sinusoidal congestion and the study groups ( $\mathrm{p}=0.017)$. The proportion of minimal sinusoidal congestion was higher in the sham $(n=6,60 \%)$ and perioperative artichoke extract $(n=4,40 \%)$ groups compared with the control group ( $\mathrm{n}=0,0 \%)$. The proportion of severe sinusoidal congestion was higher in the control group $(n=6,60 \%$ versus $n=1,10 \%$ and $n=6,60 \%$ versus $n=1,10 \%)$. A statistically significant association was determined between necrosis and the study groups $(\mathrm{p}=0.011)$. Necrosis was absent at a higher rate in the sham $(\mathrm{n}=10,100 \%)$ and perioperative artichoke extract $(n=9,90 \%)$ groups compared with the control group $(n=4$, $40 \%$ ), and the proportion of single-cell necrosis was higher in the control group ( $n=6,60 \%$ vs. $n=0,0 \%$ and $n=6,60 \%$ versus $\mathrm{n}=1,10 \%)$. No significant difference was determined between the groups regarding the rates of vacuolization $(p>0.999)$. The histopathological images of the groups are given in Figures 1-3.

\section{DISCUSSION}

I/R injury, which occurs due to hypoperfusion in the liver, causes irreversible adverse effects in many tissues and organs other than the liver. Many factors such as anaerobic metabolism, oxidative stress and ROS secretion, mitochondrial damage, and cytokines play a role in regulating hepatic I/R processes $^{16}$. Although many studies have been conducted on the application of agents with protective effects to prevent hepatic

Table 2. Average values of biochemical parameters according to groups.

\begin{tabular}{l|c|c|c|c|c}
\hline Groups & CK & TPROT & ALBUMIN & TBIL & DBIL \\
\hline $\begin{array}{l}\text { Group 1 } \\
\text { (Sham) }\end{array}$ & $2095.22 \pm 122.68^{\mathrm{a}}$ & $70.97 \pm 8.45$ & $35.65 \pm 2.39$ & $0.17 \pm 0.04$ & $0.11 \pm 0.04$ \\
\hline $\begin{array}{l}\text { Group 2 } \\
\text { (Control) }\end{array}$ & $5843.00 \pm 186.22^{\mathrm{b}}$ & $67.58 \pm 3.95$ & $34.00 \pm 2.52$ & $0.27 \pm 0.09$ & $0.16 \pm 0.09$ \\
\hline $\begin{array}{l}\text { Group 3 } \\
\text { (Artichoke) }\end{array}$ & $2791.10 \pm 100.58$ & $66.31 \pm 5.71$ & $33.73 \pm 2.32$ & $0.18 \pm 0.07$ & $0.16 \pm 0.06$ \\
\hline
\end{tabular}

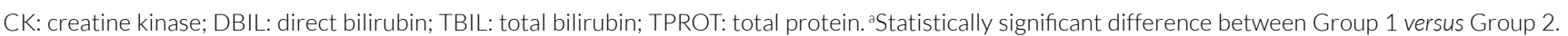
'Statistically significant difference between Group 2 versus Group 3.

Table 3. Comparisons of the histopathological scores of the study groups.

\begin{tabular}{|c|c|c|c|c|}
\hline & $\begin{array}{l}\text { Group } 1 \\
\text { (Sham) }\end{array}$ & $\begin{array}{c}\text { Group } 2 \\
\text { (Control) }\end{array}$ & $\begin{array}{l}\text { Group } 3 \\
\text { (ArtExt) }\end{array}$ & p-value \\
\hline \multicolumn{5}{|l|}{ Histopathological scores } \\
\hline Sinusoidal congestion & & & & 0.017 \\
\hline None $(n=1)$ & $1(10)$ & $\mathrm{O}(0)$ & $\mathrm{O}(0)$ & \\
\hline Minimal $(n=10)$ & $6(60)^{a}$ & $\mathrm{O}(0)^{\mathrm{b}}$ & $4(40)^{a}$ & \\
\hline Mild $(n=3)$ & $1(10)$ & $1(10)$ & $1(10)$ & \\
\hline Moderate $(n=8)$ & $1(10)$ & $3(30)$ & $4(40)$ & \\
\hline Severe $(n=8)$ & $1(10)^{a}$ & $6(60)^{b}$ & $1(10)^{a}$ & \\
\hline Necrosis & & & & 0.011 \\
\hline None $(n=23)$ & $10(100)^{a}$ & $4(40)^{b}$ & $9(90)^{\mathrm{a}}$ & \\
\hline Single-cell necrosis $(n=7)$ & $\mathrm{O}(0)^{\mathrm{a}}$ & $6(60)^{b}$ & $1(10)^{a}$ & \\
\hline Vacuolization & & & & $>0.999$ \\
\hline None $(n=38)$ & $10(100)$ & $9(90)$ & $10(100)$ & \\
\hline Minimal $(n=2)$ & $\mathrm{O}(0)$ & $1(10)$ & $\mathrm{O}(0)$ & \\
\hline
\end{tabular}

ArtExt: artichoke extract. Data are shown as number ( $n$ ) and percentage (\%). The $p$-value was calculated using $\chi^{2}$ test with Monte Carlo simulation, followed by post hoc test with Bonferroni adjustment for proportion test. Different superscript letters in each row indicate a statistically significant difference between groups. 
(A)

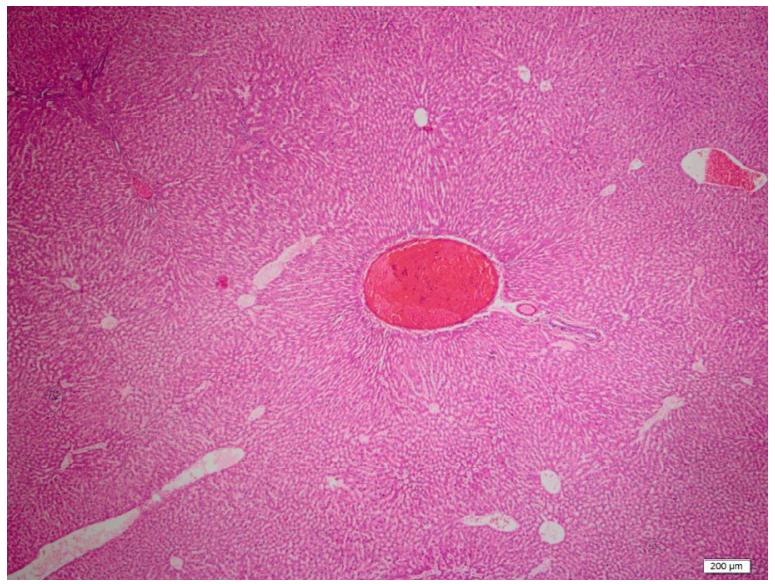

(B)

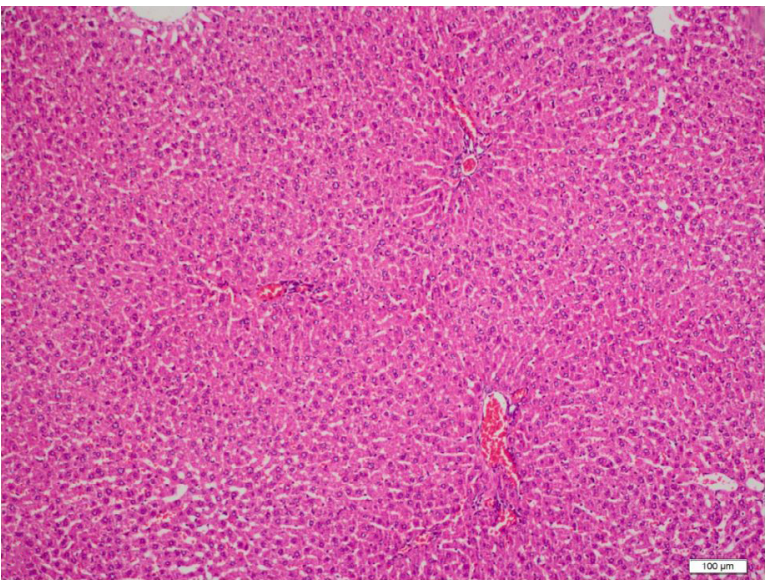

Figure 1. (A, B) Portal area and central vein observed in the liver tissue of Sham group. Portal areas and lobules are in a regular structure, with no inflammation or sinusoidal congestion (Hematoxylin and Eosine, 40×, 100×).

(A)

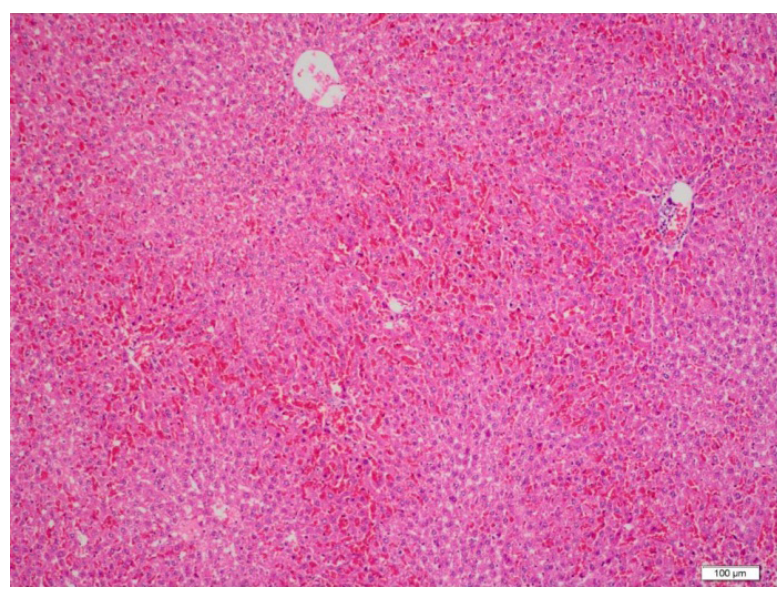

(B)

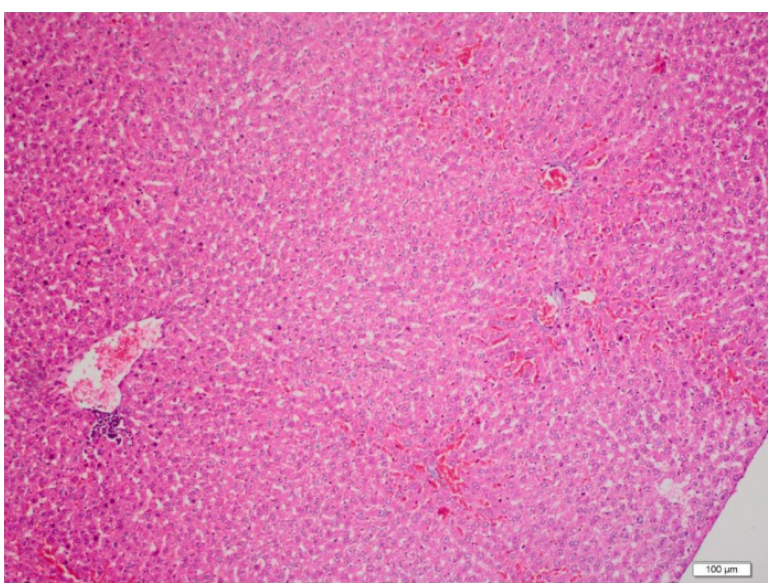

Figure 2. (A, B) In the liver tissue of Group 2, mononuclear inflammatory cells and prominent sinusoidal congestion are observed in hepatocytes around the central vein (Hematoxylin and Eosine, 100x).

(A)

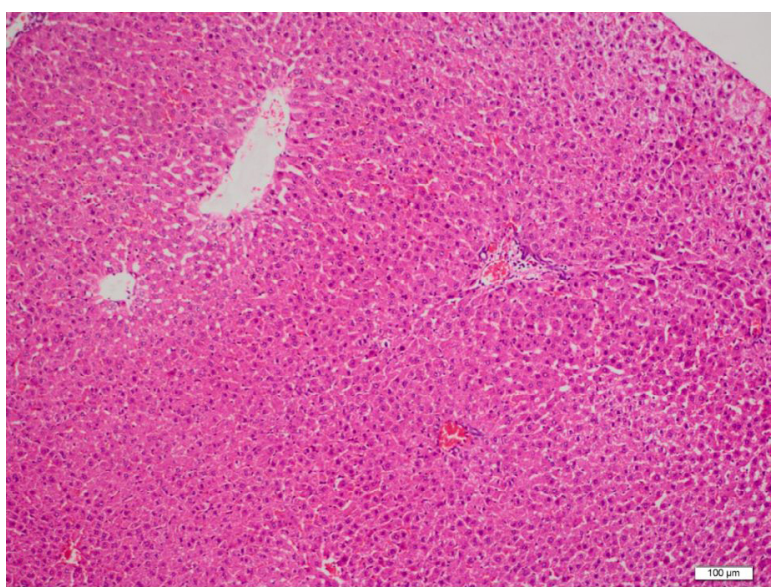

(B)

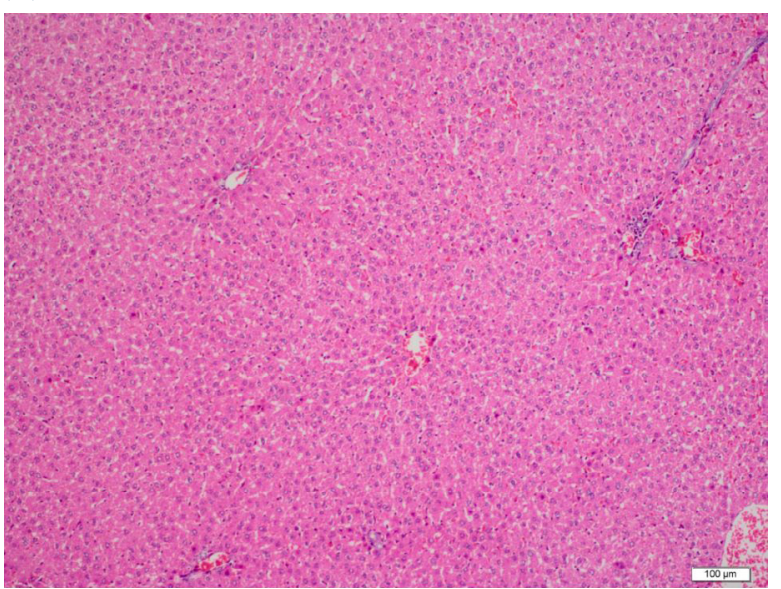

Figure 3. (A, B) Group 3 showing sparse mononuclear inflammatory cells and findings of mild sinusoidal congestion (Hematoxylin and Eosine, 100x). 
I/R injury in experimental studies, there are no studies evaluating the efficacy of ALE ${ }^{17-19}$.

Artichoke is a native plant of the Mediterranean basin, which is known worldwide for its medicinal properties, including hypoglycemic, cholesterol lowering, anti-atherosclerotic, hepatoprotective, prebiotic and probiotic, choleretic (ALE might increase secretion in perfused rat liver and liver cell cultures), antimicrobial, antifungal, immunomodulatory, and anticarcinogenic effects. However, it is accepted that the positive impact of artichoke on health is mainly related to its antioxidant and anti-inflammatory effects ${ }^{20}$.

By helping to remove ROS, ALE prevents lipid peroxidation in cell membranes and significantly prevents oxidative damage $^{20}$. In this study, with the use of ALE during I/R injury, a statistically significant improvement was observed in the ALT, AST, LDH, ALP, and CK values in plasma, which had increased as a result of membrane damage, and this was considered the hepatoprotective effect of ALE against I/R injury.

More than $80 \%$ of many proteins synthesized by the liver, such as coagulation factors, ALB, thyroid-binding globulin, and complement proteins, pass into the systemic circulation ${ }^{21}$. When the effects of liver I/R injury on blood protein levels and protein and gene expressions were evaluated in this study, there was no statistically significant difference between the sham, control, and artichoke treatment groups ( $>0.05)$. Although I/R injury is severe trauma to the liver, no difference between the groups was interpreted as the damage not being of a long-term duration to affect blood protein levels.

Mard et al. showed that Kupffer cell swelling, vasoconstriction, leukocyte infiltration, platelet aggregation, sinusoidal congestion, and central vein enlargement induce injury after hepatic I/ $\mathrm{R}^{22}$. In this study, sinusoidal congestion and necrosis were statistically significantly higher in the control group in the histopathological examination $(\mathrm{p}<0.05)$. In the light of these results, ALE can be considered to have histopathologically positive effects on liver I/R injury.

To evaluate the antioxidant activity, the antioxidant enzymes' activity (SOD, CAT, and GPx) was measured. Antioxidant

\section{REFERENCES}

1. Abd-ElbasetM,ArafaESA, El Sherbiny GA,Abdel-BakkyMS, Elgendye ANAM. Quercetin modulates iNOS, eNOS and NOSTRIN expressions and attenuates oxidative stress in warm hepatic ischemia-reperfusion injury in rats. Beni Suef Univ J Basic Appl Sci. 2015;4(3):246-55. https://doi.org/10.1016/j.bjbas.2015.07.001

2. Elias-Miró M, Jiménez-Castro MB, Rodés J, Peralta C. Current knowledge on oxidative stress in hepatic ischemia/reperfusion. Free Radic Res. 2013;47(8):555-68. https://doi.org/10.3109/10 715762.2013 .811721 activity was seen to be the highest in the artichoke group, and this difference was statistically significant when compared with the other groups $(\mathrm{p}<0.05)$.

In the evaluations made to explain the source of the hepatoprotective effect of ALE shown biochemically and histopathologically, the total phenolic and flavonoid amount of ALE was found to be $38.03 \pm 0.95 \mu \mathrm{g} \mathrm{GAE} / \mathrm{mg}$ and $18.11 \pm 0.26 \mu \mathrm{g} \mathrm{QE} / \mathrm{mg}$, respectively. Therefore, on the basis of these results, the antioxidant effect of ALE used in this study was attributed to the phenolics and flavonoids it contained.

A previous study demonstrated that Cynara scolymus extract also has anti-inflammatory properties ${ }^{23}$. In this study, CRP, one of the indicators of inflammation, was statistically significantly higher in the control group than that in the sham and artichoke groups.

\section{CONCLUSION}

In the light of the results of this study, the prepared artichoke extract can be considered to have a hepatoprotective effect against the I/R injury associated with the antioxidant and anti-inflammatory effects of the artichoke.

\section{ACKNOWLEDGEMENT}

The authors thank Asst. Prof. Muslu Kazım KÖREZ for statistical analysis.

\section{AUTHORS' CONTRIBUTIONS}

SC: Conceptualization, Writing - original draft, Writing review \& editing. KK: Conceptualization, Data curation, Formal Analysis. SK: Project administration, Formal Analysis. SH: Project administration, Formal Analysis. BÇ: Data curation, Formal Analysis, Writing - review \& editing. IB: Data curation, Formal Analysis, Writing - original draft. FS: Data curation. PC: Formal Analysis. HGB: Formal Analysis. MŞ: Writing - review \& editing.

3. Topliss J, Clark A, Ernst E, Hufford CD, Johnston G, Rimoldi J, et al. Natural and synthetic substances related to human health (IUPAC Technical Report). Pure Appl Chem. 2002;74(10): 1957-85. https://doi.org/10.1351/pac200274101957

4. El-Boshy M, Ashshi A, Gaith M, Qusty N, Bokhary T, AlTaweel N, et al. Studies on the protective effect of the artichoke (Cynarascolymus) leaf extract against cadmium toxicity-induced oxidative stress, hepatorenal damage, and immunosuppressive and hematological disorders in rats. Environ Sci Pollut Res Int. 2017;24(13):12372-83. https://doi. org/10.1007/s11356-017-8876-x 
5. Mehmetçik G, Ozdemirler G, Koçak-Toker N, Cevikba,s U, Uysal $M$. Effect of pretreatment with artichoke extract on carbon tetrachloride-induced liver injury and oxidative stress. Exp Toxicol Pathol. 2008;60(6):475-80. https://doi.org/10.1016/j. etp.2008.04.014

6. Ahmadi A, Heidarian E, Ghatreh-Samani K. Modulatory effects of artichoke (Cynara scolymus L.) leaf extract against oxidative stress and hepatic TNF- $\alpha$ gene expression in acute diazinon-induced liver injury in rats. J Basic Clin Physiol Pharmacol. 2019;30(5). https:// doi.org/10.1515/jbcpp-2018-0180

7. Panahi Y, Kianpour P, Mohtashami R, Atkin SL, Butler AE, Jafari R, et al. Efficacy of artichoke leaf extract in non-alcoholic fatty liver disease: A pilot double-blind randomized controlled trial. Phytother Res. 2018;32(7):1382-7. https://doi.org/10.1002/ptr.6073

8. Aebi H. Catalase in vitro. Methods Enzymol. 1984;105:121-6. https://doi.org/10.1016/s0076-6879(84)05016-3

9. Marklund S, Marklund G. Involvement of the superoxide anion radical in the autoxidation of pyrogallol and a convenient assay for superoxide dismutase. Eur J Biochem. 1974;47(3):469-74. https://doi.org/10.1111/j.1432-1033.1974.tb03714.x

10. Paglia DE, ValentineWN. Studies on the quantitative and qualitative characterization of erythrocyte glutathione peroxidase. J Lab Clin Med. 1967;70(1):158-69. PMID: 6066618

11. Reitman S, Frankel S. A colorimetric method for the determination of serum glutamic oxalacetic and glutamic pyruvic transaminases. Am J Clin Pathol. 1957;28(1):56-63. https://doi.org/10.1093/ ajcp/28.1.56

12. Wroblewski F, Ladue JS. Lactic dehydrogenase activity in blood. Proc Soc Exp Biol Med. 1955;90(1):210-3. https://doi. org/10.3181/00379727-90-21985

13. Lowry OH, Rosebrough NJ, Farr AL, Randall RJ. Protein measurement with the Folin phenol reagent. J Biol Chem. 1951;193(1):265-75. PMID: 14907713

14. Samadani AA, Nikbakhsh N, Fattahi S, Pourbagher R, Mir SMA, Kani NM, et al. RNA Extraction from Animal and Human's Cancerous Tissues: Does Tissue Matter? Int J Mol Cell Med. 2015;4(1):54-9. PMID: 25815283
15. Suzuki S, Toledo-Pereyra LH, Rodriguez FJ, Cejalvo D. Neutrophil infiltration as an important factor in liver ischemia and reperfusion injury. Modulating effects of FK506 and cyclosporine. Transplantation. 1993;55(6):1265-72. https://doi.org/10.1097/00007890199306000-00011

16. Cannistrà M, Ruggiero M, Zullo A, Gallelli G, Serafini S, Maria M, et al. Hepatic ischemia reperfusion injury: a systematic review of literature and the role of current drugs and biomarkers. Int J Surg. 2016;33(Suppl 1):S57-70. https://doi.org/10.1016/j. ijsu.2016.05.050

17. Selzner N, Rudiger H, Graf R, Clavien PA. Protective strategies against ischemic injury of the liver. Gastroenterology. 2003;125(3):91736. https://doi.org/10.1016/s0016-5085(03)01048-5

18. Rancan EA, Frota EI, Freitas TMN, Jordani MC, Évora PRB, CastroE-Silva O. Evaluation of Indigo carmine on hepatic ischemia and reperfusion injury. Acta Cir Bras. 2020;35(9):e202000901. https:// doi.org/10.1590/s0102-865020200090000001

19. Barlas AM, Kismet K, Erel S, Kuru S, Cavusoglu T, Senes M, et al. Erdosteine ameliorates the harmful effects of ischemia-reperfusion injury on the liver of rats. Acta Cir Bras. 2017;32(10):796-806 https://doi.org/10.1590/s0102-865020170100000001

20. SalekzamaniS,Ebrahimi-Mameghani M, Rezazadeh K. Theantioxidant activity of artichoke (Cynara scolymus): a systematic review and meta-analysis of animal studies. Phytother Res. 2019;33(1):55-71. https://doi.org/10.1002/ptr.6213

21. Charlton MR. Protein metabolism and liver disease. Baillieres Clin Endocrinol Metab. 1996;10(4):617-35. https://doi.org/10.1016/ s0950-351x(96)80771-3

22. Mard SA, Akbari G, Dianat M, Mansouri E. The Effect of zinc sulfate on miR-122, miR-34a, atioxidants, biochemical and histopathological parameters following hepatic ischemia/reperfusion injury in rats. Biol Trace Elem Res. 2019;188(2):434-40. https://doi.org/10.1007/ s12011-018-1425-8

23. Mohamed SH, Ahmed HH, Farrag ARH, Abdel-Azim N, Shahat AA, et al. Cynara scolymus for relieving on nonalcoholic steatohepatitis induced in rats. Int J Pharm Pharm Sci. 2013;5(Suppl 1):57-66. 